\title{
The analgesic efficacy of subcostal transversus abdominis plane block with Mercedes incision
}

\author{
Jian-guo Guo ${ }^{1}$, Hui-ling Li ${ }^{1}$, Qing-qing Pei ${ }^{2}$ and Zhi-ying Feng ${ }^{1 *}$ (D)
}

\begin{abstract}
Background: Conventional perioperative analgesic modalities (e.g. opioids, epidural analgesia) have their own drawbacks, which limit their clinical application. This study investigated the opioid-sparing effectsof the oblique subcostal transversus abdominis plane (OSTAP) blockade with ropivacaine for the patients undergoing open liver resection with a Mercedes incision.
\end{abstract}

Methods: 126 patients who were scheduled for open liver resection were enrolled in this study. Patients were randomly assigned to receive bilateral ultrasound-guided OSTAPblocks with either $0.375 \%$ ropivacaine (groupT) or 0 . 9\% isotonic saline (group C). Both groups also received intravenous patient-controlled analgesia and intravenous $40 \mathrm{mg}$ parecoxib every $12 \mathrm{~h}$ for a total of 3 days. Preoperative and intraoperative parameters, plus intraoperative and postoperative cumulative sufentanil consumption, were recorded.

Results: 70 patients were enrolled in the study finally. There were no significant differences between the two groups with respect to preoperative parameters, and surgical and anesthetic characteristics. The intraoperative sufentanil use, cumulative sufentanil consumption at 5 min after extubation, $2 \mathrm{~h}, 4 \mathrm{~h}, 12 \mathrm{~h}$ and $24 \mathrm{~h}$ after operation in group T was significantly less than that in group $C(P=0.001,0.001,0.000,0.000,0.001$ and 0.044 , respectively). Compared with group C, postoperative NRS pain scores at rest were significantly lower at $2 \mathrm{~h}$ and $4 \mathrm{~h}$ postoperatively in group $T(P=0.04$ and 0.02 , respectively); NRS scores at the time of coughing were also significantly lower in group $T$ than in group $C$ at all time points except 5 min after extubation (all $P<0.001$ ). Furthermore, compared with group $C$, the number of intraoperative vasodilator use, the extubation time and the incidence of nausea was reduced in group $\mathrm{T}$.

Conclusion: Ultrasound-guided OSTAP block with ropivacaine can significantly decrease the perioperative cumulative dosage of analgesics and improve analgesic effect without obvious side effects for the patients who underwent an open liver resection with Mercedes incision when compared tothe ultrasound-guided OSTAP block with saline.

Trial registration: The study protocol was registered at http://www.chictr.org.cn (ChiCTR-TRC- 14004827) on February 19, 2014.

Keywords: Postoperative pain, Transverses abdominis plane block, Liver resection, Ropivacaine

\footnotetext{
* Correspondence: fzy1972@zju.edu.cn

'Department of Anesthesiology and Pain Medicine, the First Affiliated Hospital, Zhejiang University School of Medicine, 79 Qing Chun Road, Hangzhou 310003, People's Republic of China

Full list of author information is available at the end of the article
} 


\section{Background}

Pain control is a vital component to achieve enhanced recovery after liver surgery. Effective postoperative pain control will reduce the incidenceof numerous postoperative complications, can facilitateearly mobilization and may result in earlier recovery [1]. However, optimal postoperative analgesic modalities following liver resection remain controversial $[1,2]$.Paincontrol is historically achieved by the administration of opioids, whichis associated with welldocumented side effects, such as sedation, respiratory depression,pruritus, hallucinations and postoperative nausea and vomiting (PONV). Epidural analgesia, another routinely used analgesic technique, offers equivalent or superior pain scores when compared toconventional systemic opioids. However, its utilizationis limited by perioperative coagulation dysfunction, which is typical in the patients for liver surgery and subsequent catastrophic neurologic injuries resulting from epidural haematoma [3-5]. In addition, epidural analgesia is independently associated with an increased use of blood transfusions and a longer hospital stay [5]. Enhanced recovery following hepatectomy has gained attention even though there is limited evidence on the efficacy and effectiveness of existing analgesic techniques. The oblique subcostal transversus abdominis plane (OSTAP) block has been demonstrated to improve pain-related outcomes after upper abdominal surgeries, such as laparoscopic cholecystectomy [2-4, 69]. To our knowledge, the analgesic efficacy of ultrasoundguided OSTAP blocks has not been extensively investigated in the setting of open liver surgery for patients suffering from liver cancer, especially for the roof-shaped incision, including the Mercedes incision $[3,6,9,10]$. Therefore, we tested the hypothesis that ultrasoundguided OSTAP blocks can reduce cumulativeopioid consumption for the patients undergoing liver resection with the Mercedes incision when added to conventional multimodel intravenous analgesic technique. The aim of this prospective comparative investigation was to assess the impact of OSTAP blockade in a multimodal perioperative analgesic regimen and any related side effects in patients undergoing liver resection with Mercedes incision.

\section{Methods}

This prospective,observer blinded randomized control trialwas conducted at the First Affiliated Hospital, School of Medicine, Zhejiang University in China after being approved by the Ethical Committee of Zhejiang University (Hangzhou, People's Republic of China) (Ref: 2013-662). Each patient read and signed a consent form before enrolment in the study.

\section{Participants}

From February 20,2014 to February19, 2015, 126 patients who suffered from hepatocellular carcinoma and scheduled for open liver resection were enrolled in this investigation. Inclusion criteria for open liver resection surgery included tumor size $<10 \mathrm{~cm}$; no intrahepatic or distant metastasis; no invasion of the diaphragm or surrounding tissues; indocyanine green retention rate at $15 \mathrm{~min}<15 \%$; a remnant liver volume/standard liver volume ratio of $>50 \%$ in patients with liver cirrhosis and $>35 \%$ in patients without liver cirrhosis; and Class A or B on the Child-Pugh liver function scale. Exclusion criteria were as follows: the American Society of Anesthesiologists classification (ASA) IV or above, body mass index $<18$ or $>26 \mathrm{~kg} / \mathrm{m}^{2}$, age $>65$ or $<18$ years old, currently taking contraceptives, pregnancy, inability to understand Mandarin, inability to properly describe postoperative pain to investigators (e.g. language barrier, neuropsychiatric disorder), relevant drug allergy, preexisting neuralgia, history of chronic pain, consumption of opioids within $24 \mathrm{~h}$ before surgery, alcohol or drug abuse, contraindications to peripheral nerve block (e.g. allergy to local anesthetics, coagulopathy, local or systemic infection), history of abdominal surgery or trauma, previous liver resection, rupture or bleeding of the tumor, emergency surgery for liver resection, estimated operation time of more than $6 \mathrm{~h}$, intraoperative bleeding more than $500 \mathrm{~mL}$, transplant donor liver resections, and those unable to be extubated postoperatively for any clinical reason.

\section{Randomizationand blinding}

The study was an observer blinded randomized control trial. The patients were randomly assigned to receive bilateral OSTAP blocks with either $40 \mathrm{~mL} 0.375 \%$ ropivacaine (Naropin; AstraZeneca, Sodertalje, Sweden) (group $\mathrm{T}$ ) or with $40 \mathrm{~mL} 0.9 \%$ isotonic saline (group C). No adjuvant was added to the solutions. Identical boxes containing either isotonic saline or ropivacaine were sealed and marked with the name of the project, the names of the investigators, and consecutive numbers according to a computer-generated block randomization list provided by www.random.org. Study medication was prepared by a designated nurse (LNZ, who did not participate in direct patient care). The nurse (LNZ) opened the box and drew the study medication into identical syringes. Two of the anesthesiologists (JGG, HLL) performed all intraoperative assessments, and two other investigators (SJY, LC) assessed and recorded all the postoperative data.

\section{Oblique subcostal transversus abdominis plane (OSTAP) block}

After sedation with midazolam, the same ultrasoundguided OSTAP block approach was performed bilaterally by one of two clinical investigators (JGG, HLL) in both groups. Ultrasound images were obtained using Sonosite S-Nerve ultrasound machine (Sonosite ${ }^{\oplus}$ Micromaxx, 
Bothwell, WA, USA) with the HFL38x broadband linear array probe. The ultrasound probe was obliquely placed on the upper abdominal wall. The neurofascial layer of OSTAP was identified as lying between the rectus abdominis and the transversus abdominis muscle. To perform the blocks, abdominal skin was prepared with 5\% povidone iodine solution and covered with sterile drapes. Local infiltration was performed with 1-2 $\mathrm{mL}$ of $2 \%$ lidocaine at the needle entry site. A 22G, $120 \mathrm{~mm}$ Stimuplex D Plus needle (B. Braun, Melsungen AG, Germany) was advanced using an in-plane technique until the tip lay within the neurovascular fascial plane between the rectus abdominis and the transversus abdominis muscle. Following negative aspiration, a test injection with $1 \mathrm{~mL}$ of $0.9 \%$ normal saline was performed to confirm the needle location. Then $20 \mathrm{~mL}$ ropivacaine (group T) or saline (group C) was injected with intermittent aspiration every $3-5 \mathrm{~mL}$ while observing the expansion of intermuscular plane on each side.

Sensory change was then assessed bilaterally between the midclavicular line and the midline, starting above dermatome T4 and moving caudally to dermatome L4. A pinprick was tested with a blunt needle and cold with disinfectant swabs at 10, 20 and 30 min after the OSTAP block by one clinical investigator (QQP). If the intended sensational decrease in surgical dermatomes did not occur after $30 \mathrm{~min}$, the patient was regarded as having a failed block and was excluded from further investigation during the analysis and statistic phase.

\section{Intraoperative anestheticmanagementbefore and after OSTAP placement}

All patients received a standardized anesthetic regimen. No additional preoperative medications were administered after block placement. Upon arrival in the operating room, ASA standard monitoring, including electrocardiography, non-invasive blood pressure and pulse oximetry was established. Pre-sedation heart rate (HR), systolic blood pressure (SBP), diastolic blood pressure (DBP) and mean arterial pressures (MAP) were recorded as baseline values. Supplemental oxygen (oronasal mask at $4 \mathrm{~L} / \mathrm{min}$ ) was administered. After placement of a peripheral venous catheter, a lactated Ringer's infusion was started at a maintenance rate. With proper sedation an OSTAP block was performed in both groups as stated above.

About $30 \mathrm{~min}$ after the OSTAP block, general anesthesia was induced with propofol $(0.5-2.0 \mathrm{mg} / \mathrm{kg})$, sufentanil $(0.2-0.6 \mu \mathrm{g} / \mathrm{kg})$ and rocuronium $(0.6-1.0 \mathrm{mg} /$ $\mathrm{kg})$. After endotracheal intubation, ventilation was started with oxygen and medical air $\left(\mathrm{FiO}_{2}=0.6\right)$ and ventilator settings were adjusted to maintain normocapnia. A total intravenous anesthesia technique composed of propofol, sufentanil, dexmedetomidine and intermittent rocuronium was used to maintain adequate anesthesia with bispectral index (BIS) at 40-50 (A-2000 $\mathrm{BIS}^{\mathrm{Tm}}$ monitor; Aspect ${ }^{\circ}$ Medical Systems, Inc., Natick, MA, USA). The dexmedetomidine was administrated intravenously with a loading dose of $0.5-0.7 \mu \mathrm{g} / \mathrm{kg} / \mathrm{h}$ for $10 \mathrm{~min}$ followed by a continuous infusion of $0.2 \mu \mathrm{g} / \mathrm{kg} / \mathrm{h}$ until $1-$ $1.5 \mathrm{~h}$ before abdomen closure. The propofol effect-site target concentrations were titrated to keep BIS between 40 and 50. If MAP or HR of the patient increased up to $20 \%$ of the initial value, intravenous sufentanil $0.05 \mu \mathrm{g} / \mathrm{kg}$ was administered. Repeated doses of sufentanil were given every $5 \mathrm{~min}$ to keep the blood pressure around the patient's baseline values. The amount of sufentanil required was documented. If the MAP or HR of the patient decreased up to $20 \%$ of the initial value, the propofol effectsite target concentrations were adjusted first; if BIS was in the range of $40-50$, ephedrine $5 \mathrm{mg}$ intravenously was administered, and additional doses of ephedrine were permitted every 2 min to maintain haemodynamic stability. The patient's nasopharyngeal temperature was maintained between $36.0{ }^{\circ} \mathrm{C}$ and $36.5^{\circ} \mathrm{C}$ by WarmTouch ${ }^{\text {rm }}$ (Covidien, Bishop's Stortford, UK). An independent anesthesiologist (QQP), who wasblinded to the mode of perioperative analgesia, would then complete the recording of the haemodynamic parameters after the bilateral OSTAP blocks.

A Mercedes incision was made about 40 min after the bilateral OSTAP blocks. The subsequent surgical procedure was performed according to the institutional standards by four surgical groups. At the end of the surgeries, these patients were then transferred to the postanesthetic care unit (PACU). Each patient's trachea was extubated when extubation criteria, including a response to verbal commands, a spontaneous respiratory rate exceeding 12 breaths $/ \mathrm{min}$, Vt more than $5 \mathrm{~mL} / \mathrm{kg}$, endtidal carbon dioxide partial pressure $<45 \mathrm{mmHg}$, and $\mathrm{SPO}_{2}$ more than $92 \%$, were met.

\section{Postoperative analgesia and antiemetic use}

Before the day of the operation, all patients were familiarized with the verbal numerical rating scale (NRS) evaluation ranging from 0 (no pain) to 10 (the worst imaginable pain). A standardized postoperative analgesic regimen was used, which consisted of $40 \mathrm{mg}$ parecoxib (diluted in $4 \mathrm{~mL} \mathrm{NS}$ ) every $12 \mathrm{~h}$ initiated $30 \mathrm{~min}$ before surgery intravenously for a total of 3 days unless contraindicated due to renal insufficiency or coronary heart disease, etc. The patient controlled analgesia (PCA) device (a PCA pump; GemStar ${ }^{\circ}$, Hospira Inc. Lake Forest, IL, USA) was connected at the end of surgery and was set to deliver a bolus of $2 \mu \mathrm{g}$ of sufentanil with a lockout time of $10 \mathrm{~min}$ with a continuous infusion at $1 \mu \mathrm{g} / \mathrm{h}$. Local anesthetics were not infiltrated into the surgical wound intraoperatively. All patients received antibiotic 
and regular ondansetron $4 \mathrm{mg}$ per day for PONV prophylaxis until 3 days postoperatively.

Upon extubation, the pain score at rest and on coughing were evaluated by nurses (SJY and LC) who were blinded to the groups using NRS (0-10). All patients received intravenous sufentanil $(2 \mu \mathrm{g})$ titration from the PCA device bolus at $10 \mathrm{~min}$ intervals if their NRS scores were $>3$ in PACU. An acute pain service team was responsible for maintenance of the PCA pump according to the hospital standard. Transition from PACU to the surgical ward was considered safe when the patient had achieved $>9$ in the modified Aldrete score for at least $10 \mathrm{~min}$. In the ward, pain at rest and on coughing was recorded for each patient using NRS $(0-10)$ at $2,4,12$, 24 and $48 \mathrm{~h}$ after the operation by the research staff. Rescue opioid with intravenous sufentanil was provided by PCA pump bolus when needed. If the patients had inadequate analgesia after 3-5 bolus doses of sufentanil, the acute pain service (APS) staff would increase the bolus dose by $20-25 \%$. If the patient was not satisfied by sufentanil PCA, intramuscular tramadol was administered for breakthrough pain by physicians on the ward. Sedation levels were recorded using the Ramsay Sedation Scale. Excessive sedation was defined as a Ramsay Sedation Scale value of 5 or 6 , which required the administration of naloxone.

\section{Data collection}

Preoperative and intraoperative variables included age, gender, weight, height, ASA physical status, liver function tests; estimated intraoperative blood loss $(\mathrm{mL})$; operative time ( $\mathrm{min}$ ); anesthesia time (defined as the time spent in the operating room in minutes); dosage of intraoperative sufentanil administered. Postoperative variables included NRS scores, cumulative sufentanil consumption, the incidence of PONV. Ramsay Sedation Scale scores [11] collected 5 min after extubation, and $2 \mathrm{~h}, 4 \mathrm{~h}, 12 \mathrm{~h}$ and $24 \mathrm{~h}$ after the operation was evaluated as: [1] the patient is anxious and agitated or restless, or both; [2] the patient is co-operative, oriented and tranquil; [3] the patient responds to commands only; [4] the patient exhibits brisk response to light glabellar tap or loud auditory stimulus; [5] the patient exhibits a sluggish response to light glabellar tap or loud auditory stimulus; and [6] the patient exhibits no response.

Dermatome sensory distribution was recorded $30 \mathrm{~min}$ after the OSTAP blockade. The incidence of accidental vascular or intraperitoneal puncture, and symptoms suggestive of local anesthetic toxicity were also recorded. All patients were interviewed until $48 \mathrm{~h}$ postoperatively. Complications, such as bruises and swelling at the block site, were followed up and managed by APS until completely resolved. The haemodynamic parameters were recorded after the OSTAP blockade at the following time points: $\mathrm{T}_{0}$, just before the OSTAP blockade; $\mathrm{T}_{1}$, 5 min after the OSTAP blockade; $\mathrm{T}_{2}, 10 \mathrm{~min}$ after the OSTAP blockade; $\mathrm{T}_{3}, 20$ min after the OSTAP blockade; $\mathrm{T}_{4}, 30$ min after the OSTAP blockade, $\mathrm{T}_{5}$, just before incision; $\mathrm{T}_{6}, 3 \mathrm{~min}$ after incision; $\mathrm{T}_{7}, 5 \mathrm{~min}$ after incision; $\mathrm{T}_{8}, 10 \mathrm{~min}$ after laparotomy; $\mathrm{T}_{9}, 30 \mathrm{~min}$ after laparotomy; and $\mathrm{T}_{10}, 48 \mathrm{~h}$ after the operation.

\section{Sample size}

The primary outcome was cumulative sufentanil consumption24h after surgery(intraoperative sufentanilconsumptionand $24 \mathrm{~h}$ after operationsufentanilconsumption) in this study. The secondary outcome included the time required to extubate, postoperative NRS scores, side effects, and haemodynamic variations perioperatively. In our preliminary trial of 18 patients, the cumulative sufentanil consumptionwere $89.45 \pm 15.5 \mu \mathrm{g}$ and $80.35 \pm 12$. $89 \mu \mathrm{g}$ in group $\mathrm{C}$ and in group $\mathrm{T}$ within $24 \mathrm{~h}$ after surgery, respectively. According to the preliminary study, we calculated that 32 patients would be required in each group for a $90 \%$ power to detect $10 \%$ reduction of cumulativesufentanil consumption at the $\alpha$ level of 0.05 . To account for any patient dropouts or missing data, we planned to enroll 40 patients per study group.

\section{Statistical analysis}

Data were analyzedusing SPSS 19.0 software (SPSS, Inc., Chicago, IL, USA). The Kolmogorov-Smirnov test was used to check for normal distribution. Parametric data were expressed as mean with95\% confidence intervalsand nonparametric data as median with interquartile range. Group means were compared using the Student's t-test or the Mann-Whitney $U$ test as appropriate. For continuous data, overall differences were tested by analysis of variance (ANOVA) followed by a post hoc test with least significant difference t-test (LSD) or KruskalWallis test followed by a Mann-Whitney $U$ test when appropriate. Categorical variables were presented as values and percentages and were compared using the $x^{2}$ test. Significance was defined as $P<0.05$.

\section{Results}

A total of 126 patients were assessed for eligibility; 19 did not meet the inclusion criteria; 27 refused to participate. A total of 10 patients were excluded from the final analysis because of a change of operative plan $(n=1)$; failure to complete the $30 \mathrm{~min}$ observation period after OSTAP $(n=2)$; intraoperative bleeding $>500 \mathrm{~mL}(\mathrm{n}=1)$; operative time $>6 \mathrm{~h}(\mathrm{n}=2)$; unplanned postoperative mechanical ventilation $(n=3)$; and failed blockade in group $\mathrm{T}(\mathrm{n}=1)$. Data were analyzedon 35 patients in each group (Fig 1). 


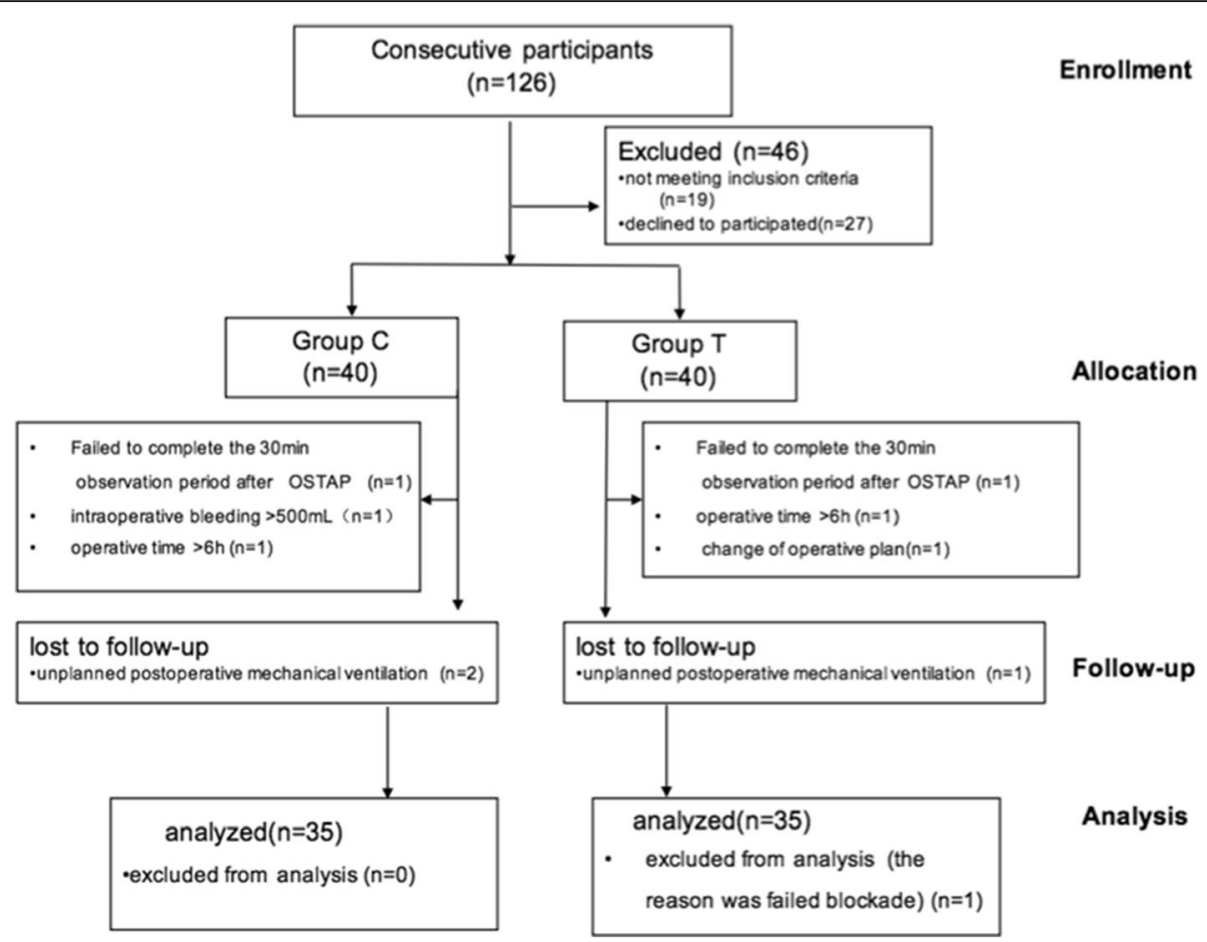

Fig. 1 Flow diagram of enrolment

\section{Preoperative parameters}

The demographics and preoperative details of the remaining 70 patients are presented in Table 1 . There were no significant differences between the two groups with respect to age, weight, ASA class, past medical history of diabetes or hypertension, preoperative laboratory studies, including international normalized ratio, prothrombin time, total bilirubin and aspartate aminotransferase.

\section{Intraoperative parameters}

Surgical and anesthetic characteristics are shown in Table 2. No significant differences were observed in incision length, time from classic TAP block to incision, operative time, estimated intraoperative blood loss and intravenous cystaloids administered between group $\mathrm{C}$ and group $\mathrm{T}$. In addition, no significant difference was found among the five surgical teams or anesthetists between the two groups. In group $\mathrm{T}$, less intraoperative propofol dosage was required compared with group C, but the difference was not statistically significant (Table 2). Compared with group $C$, the time to extubation was significantly shorter in group $\mathrm{T}(P=0.02)$. There were no differences between the two groups regarding the number of patients using ephedrine (vasopressor). However, the number of patients that required a vasodilator intraoperatively in group $\mathrm{T}$ was significantly less than that in group $\mathrm{C}(P=0.002)$.
Table 1 Patient demographic characteristics, comorbidity and liver function tests before surgery in Groups $C$ and $T$

\begin{tabular}{llll}
\hline Variables & Group C $(n=35)$ & Group T(n=35) & Pvalue \\
\hline Gender (female/male) & $12 / 23$ & $10 / 25$ & 0.797 \\
Age $(y)$ & $52.6(49.7-55.5)$ & $49.1(44.8-53.3)$ & 0.166 \\
Body weight $(\mathrm{kg})$ & $62.5(60.0-65.4)$ & $58.9(56.1-61.7)$ & 0.092 \\
Height $(\mathrm{cm})$ & $166.5(164.2-169.2)$ & $165.1(163.1-167.2)$ & 0.389 \\
BMI(kg/m2) & $23.1(21.9-25.6)$ & $22.2(19.4-23.3)$ & 0.108 \\
Preoperative & & & \\
ASA (I/II/II) & $6 / 25 / 5$ & $5 / 25 / 5$ & 0.962 \\
Hypertension & 4 & 2 & 0.673 \\
Diabetes & 2 & 1 & 1.000 \\
ALB value (g/L) & $39.4(38.1-40.7)$ & $39.7(38.1-41.4)$ & 0.741 \\
AST value(u/L) & $24.0(20.0-31.0)$ & $26.0(19.0-41.0)$ & 0.708 \\
TB ( $\mu$ mol/L) & $14.5(10.8-18.3)$ & $13.0(10.0-16.0)$ & 0.393 \\
BUN value(mmol/L) & $5.2(4.6-5.6)$ & $5.2(4.6-5.7)$ & 0.959 \\
CR (umol/L) & $65.2(61.8-70.2)$ & $69.1(64.2-74.0)$ & 0.235 \\
INR value & $1.1(1.0-1.2)$ & $1.1(1.0-1.2)$ & 0.640 \\
PT value(s) & $12.5(11.8-13.3)$ & $12.9(11.4-13.7)$ & 0.428 \\
\hline
\end{tabular}

Values are expressed as mean (95\%confidence interval) for normal distributed variables, median (interquartile range) for skew distribution, and numbers for absolute values

ALB Serum albumin, AST Aspartate aminotransferase, BMI Body mass index, $B U N$ Blood urea nitrogen, $C R$ Serum creatinine, INR International normalized ratio, PT Prothrombin time, SA American Society of Anesthesiologists, TB

Total bilirubin

${ }^{*} P<0.05$ compared to the control group 
Table 2 Surgical and anesthetic characteristics in Groups $C$ and $T$

\begin{tabular}{|c|c|c|c|}
\hline Variables & Group C $(n=35)$ & Group T $(n=35)$ & $P$ value \\
\hline Time from TAP to incision(min) & $47.0(44.3-50.2)$ & $46.9(43.5-47.8)$ & 0.626 \\
\hline Incision length(cm) & $30.0(23.8-35.0)$ & $25.0(20.0-35.0)$ & 0.703 \\
\hline Operation time(min) & 193.9(172.7-287.1) & 193.8(159.7-261.9) & 0.377 \\
\hline Intraoperative intravenous crystalloids & $2250(1750-3030)$ & $2250(1750-3120)$ & 0.872 \\
\hline Estimated blood loss (mL) & $200.0(100.00-350.0)$ & $200.0(100.0-400.0)$ & 0.345 \\
\hline Urine output $(\mathrm{mL})$ & $200.0(150.0-400.0)$ & $200.0(140.0-400.0)$ & 0.894 \\
\hline Intraoperative Propofol(mg) & 1168.7(986.0-1681.1) & $1121.7(866.1-1291.2)$ & 0.276 \\
\hline Extubation time(min) & $59.9(51.7-85.0)$ & $45.35(39.9-61.25)^{*}$ & 0.022 \\
\hline Surgeon & & & 0.097 \\
\hline Group 1 & 10 & 10 & \\
\hline Group 2 & 3 & 0 & \\
\hline Group 3 & 11 & 5 & \\
\hline Group 4 & 7 & 13 & \\
\hline Group 5 & 4 & 7 & \\
\hline Anesthetist & & & 0.632 \\
\hline Group 1 & 19 & 17 & \\
\hline Group 2 & 16 & 18 & \\
\hline Intraoperative ephedrine use & & & 1.000 \\
\hline yes(n) & 4 & 5 & \\
\hline $\mathrm{No}(\mathrm{n})$ & 31 & 30 & \\
\hline Intraoperative antihypertensives & & & 0.002 \\
\hline yes(n) & 24 & $10^{*}$ & \\
\hline $\mathrm{No}(\mathrm{n})$ & 11 & 25 & \\
\hline
\end{tabular}

Values are expressed as mean (95\%confidence interval) for normal distributed variables, median (interquartile range) for skew distribution, and numbers for absolute values

TAP transversus abdominis plane

${ }^{*} P<0.05$ compared with Group $C$

\section{OSTAP blockade}

In both groups, the OSTAP was easily performed using ultrasonography, and the procedures were carried out without any complications. During statistics, the effect of OSTAP blockade was checked one by one in both groups. In group $\mathrm{C}$, no patients had the dermatome sensory distribution by pinprick approach. One patient had failed blocks in Group $\mathrm{T}$ and was excluded from the final analysis. The OSTAP block in group $\mathrm{T}$ resulted in a distribution of sensory block ranging from $\mathrm{T} 5$ to T11 (Fig. 2). None of the patients suffered from any complications related to the bilateral OSTAP block, such as vascular or intraperitoneal puncture, local anesthetics systemic toxicity, bruises or swelling at the block site.

\section{Perioperative pain control}

The intraoperative sufentanil use in group $\mathrm{T}$ was significantly less than that in group C $(P=0.001)$. Compared with group $C$, cumulative sufentanil consumption at 5 min after extubation, and $2 \mathrm{~h}, 4 \mathrm{~h}, 12 \mathrm{~h}$ and $24 \mathrm{~h}$ after the operation was significantly lower in group $\mathrm{T}(\mathrm{P}=0$.
001, 0.000, 0.000, 0.001 and 0.044, respectively) (Fig 3). Nevertheless, no significant difference was found in the cumulative sufentanil consumption at $48 \mathrm{~h}$ after opertation between the two groups $(P=0.181)$. Following discharge from the recovery unit to the one-day surgery ward, there were no differences between the groups in the requirements for non-opioid analgesic medication. However, four patients in group $\mathrm{C}$ and one in group $\mathrm{T}$ could not be satisfied by sufentanil PCA and they received intramuscular tramadol $100 \mathrm{mg}$ for breakthrough pain. Group $C$ required more rescue tramadol compared to group $\mathrm{T}$, but the difference was not statisticallysignificant $(P>0.05)$.

Both groups delivered good analgesia at rest. However, compared with group $C$, the OSTAP block significantly reduced postoperative NRS pain scores at rest, with (median (interquartile range)) at $2 \mathrm{~h}$ after the operation $(2[1,2]$ vs. $2[1-3])$ and $4 \mathrm{~h}$ after the operation $(1[1,2]$ vs $2[1-3])$. NRS scores at the time of coughing were also significantly lower in group $\mathrm{T}$ than in group $\mathrm{C}$ at all time points except 5 min after extubation (all $P<0.001$ ) (Table 3). 


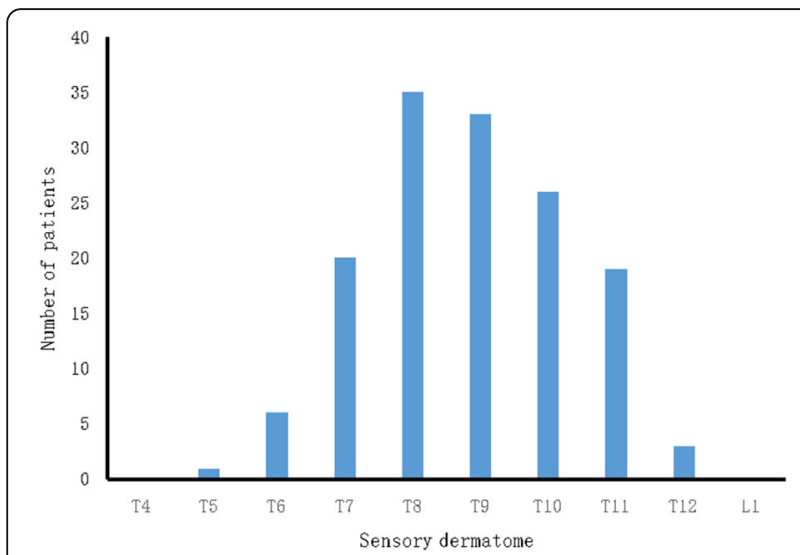

Fig. 2 Sensory dermatomal distribution in group T at 30 min after oblique subcostal transversus abdominis plane block

\section{Nausea, vomiting and sedation}

Compared to group $\mathrm{T}$, group $\mathrm{C}$ demonstrated a higher incidence of nausea between $4 \mathrm{~h}$ and $8 \mathrm{~h}$ after the operation $(22.9 \%$ vs $5.71 \% ; P<0.05)$. However, there were no significant differences on the sedation score, the number of times of vomiting and hypotension postoperatively $(P>0.05$; Fig. 4). The incidence of pruritus was very low, and there was no significant difference between both groups ( 1 vs. 1 postoperatively; $P>0.05$ ) (Table 4 ).

\section{Hemodynamics}

According to the protocol, the hemodynamics parameters were also recorded before and after the OSTAP block and at incision. There were no significant differences between baseline values of $\mathrm{HR}\left(\mathrm{T}_{0}\right)$ and at $\mathrm{T}_{1}$ through $\mathrm{T}_{10}$. In addition, there was no statistically

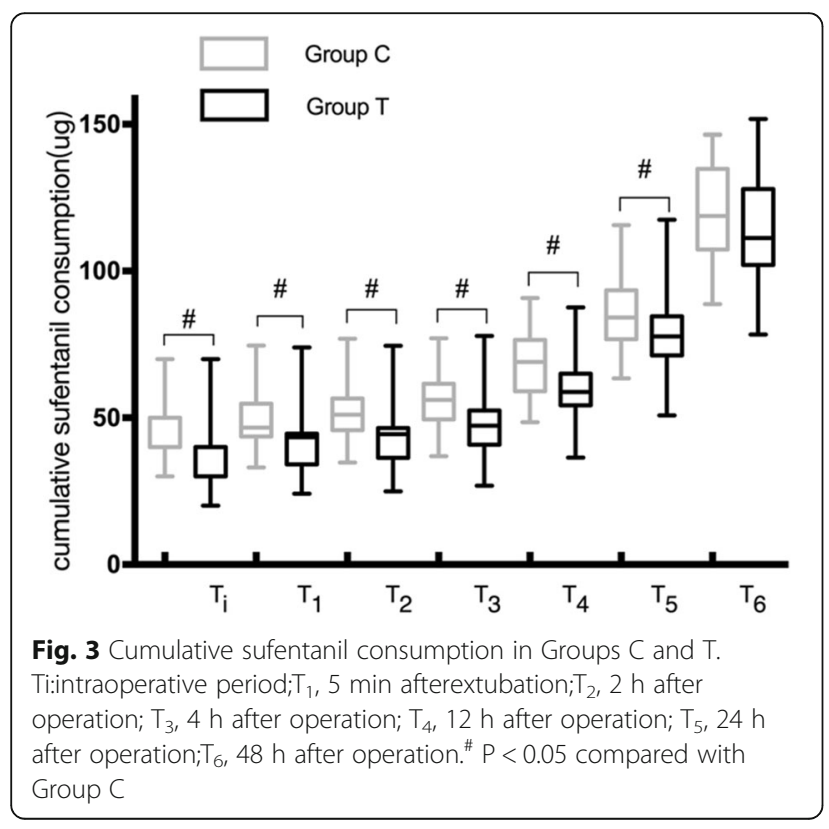

Table 3 Postoperative verbal numerical rating scale (NRS) scorein Groups $C$ and $T$

\begin{tabular}{llll}
\hline Variables & Group C $(n=35)$ & Group $T(n=35)$ & $P$ value \\
\hline \multicolumn{2}{l}{ NRS score at rest } \\
$T_{1}$ & $2(1-4)$ & $2(1-3)$ & \\
$T_{2}$ & $2(1-3)$ & $2(1-2)^{*}$ & 0.070 \\
$T_{3}$ & $2(1-3)$ & $1(1-2)^{*}$ & 0.044 \\
$T_{4}$ & $2(1-3)$ & $2(1-3)$ & 0.024 \\
$T_{5}$ & $1(1-2)^{\#}$ & $1(1-2)$ & 0.070 \\
$T_{6}$ & $1(1-2)^{\#}$ & $1(1-2)^{\#}$ & 0.402 \\
\end{tabular}

NRS score at cough

$\begin{array}{llll}\mathrm{T}_{1} & 4(2-9) & 4(2-7) & 0.186 \\ \mathrm{~T}_{2} & 4(3-7) & 3(1-5)^{* \#} & <0.001 \\ \mathrm{~T}_{3} & 4(3-8) & 3(1-4)^{* \#} & <0.001 \\ \mathrm{~T}_{4} & 4(3-7) & 2(1-6)^{* \#} & <0.001 \\ \mathrm{~T}_{5} & 3(2-6) & 2(1-6)^{* \#} & <0.001 \\ \mathrm{~T}_{6} & 3(2-6)^{\#} & 2(1-5)^{* \#} & <0.001\end{array}$

Values are expressed as median (interquartile range) for skew distribution. NRS, verbal numerical rating scale; $\mathrm{T}_{1}, 5$ min afterextubation; $\mathrm{T}_{2}, 2 \mathrm{~h}$ after operation; $T_{3}, 4 \mathrm{~h}$ after operation; $T_{4}, 12 \mathrm{~h}$ after operation; $T_{5}, 24 \mathrm{~h}$ after operation; $\mathrm{T}_{6}, 48 \mathrm{~h}$ after operation

${ }^{\#} P<0.05$ compared to $\mathrm{T}_{1} ;{ }^{*} P<0.05$ compared with Group $C$

significant difference of HR between the two groups at all time points $(P>0.05$; Fig. 4$)$. Compared to baseline values, the MAP after laparotomy was significantly higher in both groups $(P<0.05$; Fig. 3); however, there was no significant difference between the two groups ( $P>0.05$; Fig. 4). Moreover, there was no significant difference in HR and oxygen saturation by pulse oximetry $\left(\mathrm{SpO}_{2}\right)$ between the two groups $(\mathrm{P}>0.05$; data not shown).

\section{Postoperative complications}

No patients suffered from liver dysfunction postoperatively. Postoperative complications included pulmonary infection (four in group $\mathrm{C}$ and two in group $\mathrm{T}$ occurred 3 days after the operation, $\mathrm{P}>0.05$ ) and renal insufficiency (one in group T 2 days postoperatively, $\mathrm{P}>0.05$ ). Finally, all the patients were discharged home in a good condition.

\section{Discussion}

To our knowledge, this was the first observe blinded randomized and controlled study to evaluate the use of the OSTAP blockade for patients undergoing an open liver resection with a Mercedes incision. We found that when comparing the control group OSTAP with saline, the ropivacaine OSTAP blockade had improved perioperative analgesia with decreased opioid use both intraoperatively and postoperatively. Furthermore, the ropivacaine OSTAP blockade decreased the intraoperative vasodilator use, the extubation time, the incidence 


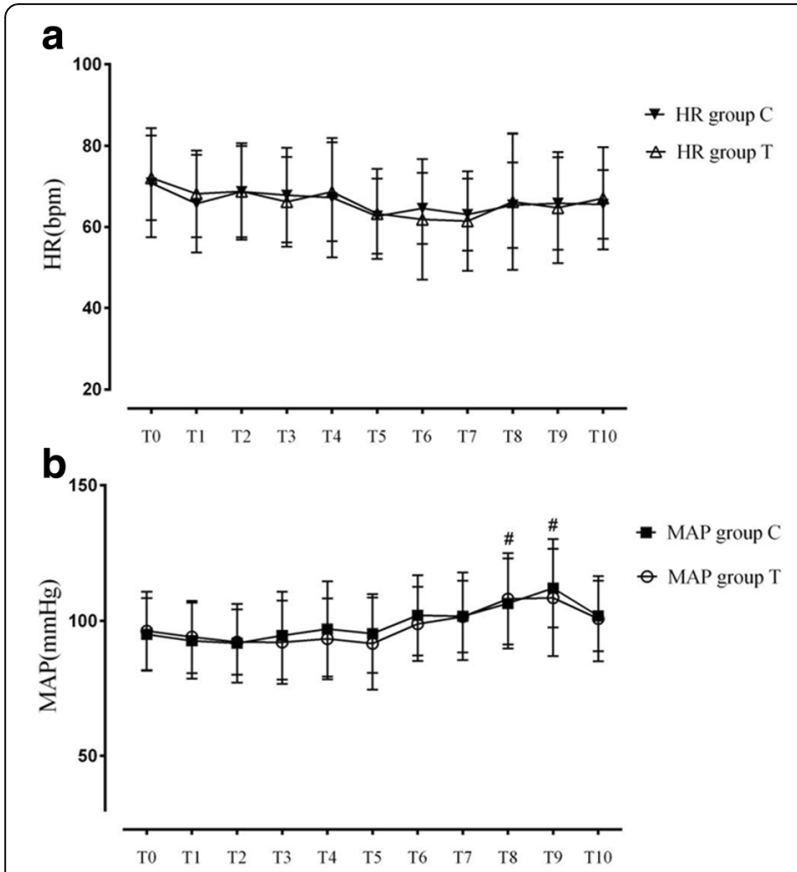

Fig. 4 The hemodynamic changes after OSTAP blockage in both groups. a: The changes of perioperative heart rate after OSTAP blockage in both groups. $\mathbf{b}$ : The changes of perioperative mean arterial pressure after OSTAP blockage in both groups. $T_{0}$ : just before OSTAP blockage; $T_{1}: 5$ min after OSTAP blockage; $T_{2}: 10$ min after OSTAP blockage; $T_{3}: 20 \mathrm{~min}$ after OSTAP blockage; $\mathrm{T}_{4}: 30 \mathrm{~min}$ after OSTAP blockage; $T_{5}$ : just before incision; $T_{6}: 3$ min after incision; $T_{7}$ : 10 min after incision; $T_{8}: 10$ min after laparotomy; $T_{9}: 15$ min after laparotomy; $\mathrm{T}_{10}$ : $30 \mathrm{~min}$ after laparotomy. $\mathrm{HR}=$ heart rate; $\mathrm{MAP}=$ mean arterial pressure; OSTAP = oblique subcostal transversus abdominis plane. ${ }^{\#} P<0.05$ compared to $T_{0} ;{ }^{*} P<0.05$ compared with group $C$

of nausea, and the pain scores, which were reported from 0 to $4 \mathrm{~h}$ postoperatively. It demonstrated that the OSTAP blockade with ropivacine offers postoperative analgesic benefit for the Mercedes incision in patients undergoing hepatectomy.

Liver cancer is one of the most common malignancies worldwide, especially in China. Hepatic resection is currently the best choice among all therapeutic strategies. As part of the multimodal approach for perioperative analgesia, classic TAP block has been widely accepted in patients who have undergone lower abdominal surgery, with an evident reduction of the morphine requirement within the first $24 \mathrm{~h}$ postoperatively, and a significant decrease of opioid-related side effects, such as PONV [2, $7,9,12-14]$. There are three common approaches of performing a TAP blockade: subcostal, classic midaxillary and ilioinguinal-iliohypogastric. The distribution of local anesthetic and the extent of sensory blockade differ among these three approaches [9, 12]. For the upper abdomen operation, Hebbard [15] originally described the OSTAP approach in 2008, which was thought to exhibit
Table 4 Postoperative nausea, vomiting, hypotension and sedation scoresin Groups $C$ and $T$

\begin{tabular}{|c|c|c|c|}
\hline Variables & Group C $(n=35)$ & Group $\mathrm{T}(n=35)$ & $P$ value \\
\hline \multicolumn{4}{|c|}{ Nausea(n) } \\
\hline $\mathrm{T}_{1}-\mathrm{T}_{2}$ & 1 & 0 & 0.31 \\
\hline $\mathrm{T}_{2}-\mathrm{T}_{3}$ & 1 & 2 & 0.56 \\
\hline $\mathrm{T}_{3}-\mathrm{T}_{4}$ & 8 & $2^{*}$ & 0.04 \\
\hline $\mathrm{T}_{4}-\mathrm{T}_{5}$ & 1 & 2 & 0.56 \\
\hline $\mathrm{T}_{5}-\mathrm{T}_{6}$ & 6 & 3 & 0.28 \\
\hline \multicolumn{4}{|c|}{ Vomiting(n) } \\
\hline $\mathrm{T}_{1}-\mathrm{T}_{2}$ & 1 & 0 & 0.31 \\
\hline$T_{2}-T_{3}$ & 1 & 1 & 1.00 \\
\hline$T_{3}-T_{4}$ & 4 & 2 & 0.39 \\
\hline $\mathrm{T}_{4}-\mathrm{T}_{5}$ & 1 & 1 & 1.00 \\
\hline $\mathrm{T}_{5}-\mathrm{T}_{6}$ & 1 & 2 & 0.56 \\
\hline \multicolumn{4}{|c|}{ Hypotension(n) } \\
\hline $\mathrm{T}_{1}-\mathrm{T}_{2}$ & 1 & 0 & 0.3 \\
\hline $\mathrm{T}_{2}-\mathrm{T}_{3}$ & 2 & 2 & 1.00 \\
\hline $\mathrm{T}_{3}-\mathrm{T}_{4}$ & 2 & 1 & 0.56 \\
\hline $\mathrm{T}_{4}-\mathrm{T}_{5}$ & 0 & 0 & 1.00 \\
\hline$T_{5}-T_{6}$ & 0 & 1 & 0.31 \\
\hline \multicolumn{4}{|c|}{ RAMSAY score } \\
\hline $\mathrm{T}_{1}$ & $2.66(2.42-2.89)$ & $2.57(2.35-2.80)$ & 0.594 \\
\hline $\mathrm{T}_{2}$ & $2.14(2.00-2.29)^{\#}$ & $2.09(1.99-2.18)^{\#}$ & 0.514 \\
\hline $\mathrm{T}_{3}$ & $2.03(1.97-2.09)^{\#}$ & $2.03(1.97-2.09)^{\#}$ & 0.514 \\
\hline $\mathrm{T}_{4}$ & $2.00(1.83-2.06)^{\#}$ & $1.94(1.83-2.01)^{\#}$ & 0.321 \\
\hline $\mathrm{T}_{5}$ & $1.97(1.91-2.03)^{\#}$ & $2.00(2.00-2.00)^{\#}$ & 0.321 \\
\hline $\mathrm{T}_{6}$ & $1.97(1.91-2.03)^{\#}$ & $2.00(2.00-2.00)^{\#}$ & 0.321 \\
\hline
\end{tabular}

Values are expressed as median (interquartile range) for normal distributed variables, median (interquartile range) for skew distribution, and numbers for absolute values. $\mathrm{T}_{1}, 5 \mathrm{~min}$ afterextubation; $\mathrm{T}_{2}, 2 \mathrm{~h}$ after operation; $\mathrm{T}_{3}, 4 \mathrm{~h}$ after operation; $\mathrm{T}_{4}, 12 \mathrm{~h}$ after operation; $\mathrm{T}_{5}, 24 \mathrm{~h}$ after operation; $\mathrm{T}_{6}, 48 \mathrm{~h}$ after operation

${ }^{\#} P<0.05$ compared to $T_{1} ;{ }^{*} P<0.05$ compared with Group $C$

effective analgesia involving dermatomes T6-T10 (for upper abdominal surgery). Lee et al. [16] found that the subcostal approach may block as cephalad as T8 (interquartile range T7-T9). Recently, the OSTAP block was reported to produce better analgesia than the classic TAP block or intravenous opioid analgesia during the first postoperative $24 \mathrm{~h}$ period in patients undergoing laparoscopic cholecystectomy [17]. Based on this investigation, we used the subcostal approach to perform a TAP block for open hepatectomy. Our findings were in agreement with existing investigations on upper abdominal surgery with a bilateral OSTAP blockade [7-9, 18-20].

To our knowledge,there are few reports on the use of the TAP block for major hepatobiliary surgery $[3,6,10]$. Eldin et al. [3] demonstrated that combining postoperative continuous TAP (3 days) and intravenous PCA 
improved postoperative pain management and reduced fentanyl consumption, with a shorter stay in the intensive care unit for the patient undergoing liver resection with an inverted L-shape incision. The most common approaches for hepatectomy are midline, J-shaped, and Mercedes incisions. Usually, the incision type used depends on the surgeon's preference and experience. Demirbas et al. [21] concluded that the duration of analgesics use was longer in the J-shaped incision than in the Mercedes incision. Mercedes incisions have been the most frequently used by our liver surgeons for adequate exposure of the liver from surrounding structures. This incision was performed along the path of vessels and nerves, which resulted in lighter tension on the incision and less damage to vessels and nerves of the abdominal wall. Moreover, this incision has been reported to provide faster healing and a better cosmetic outcome.

A recent meta-analysis [8] suggested that the optimal time for TAP block placement should be preoperatively, as opioid requirement and pain score were significantly reduced in comparison with that of TAP block performed postoperatively. In this investigation, we performed the OSTAP block before general anesthesia induction and endotracheal intubation. Our results showed that several intraoperative parameters in group $\mathrm{T}$, including sufentanil dosage, the number of patients who used a vasodilator and the time to extubation, were significantly less than those in group C. Compared with group $\mathrm{C}$, cumulative sufentanil consumption till postoperative $24 \mathrm{~h}$ and NRS pain scores at $2 \mathrm{~h}$ and $4 \mathrm{~h}$ postopertively decreased significantly in group T. Our results were consistent with previous findings where TAP blocks have been described to last from $6 \mathrm{~h}$ to $24 \mathrm{~h}$ using ropivacaine $[7,16,22-24]$. The duration of the peripheral nerve block depends on several factors, such as the choice of local anesthetics, the site of injection and the presence of adjuncts. Ropivacaine is the most frequently used local anesthetic for peripheral nerve block in the People's Republic of China [22]. Lee et al. [16] demonstrated that maximal dermatome spread was observed at $30 \mathrm{~min}$ and usually regressed by $24 \mathrm{~h}$. Although few studies have shown the analgesic effect lasting longer than $24 \mathrm{~h}$ [25], Stoving et al. [24] demonstrated that the blockade duration of ultrasoundguided unilateral TAP block with $20 \mathrm{~mL} 75 \mathrm{mg} / \mathrm{mL}$ ropivacaine was approximately $10 \mathrm{~h}$ with a large variation in healthy volunteers. A meta-analysis about the analgesic efficacy of TAP in 31 controlled trials including 1611 adult participants who underwent abdominal laparotomy, abdominal laparoscopy, or caesarean delivery, showed that pain scores at rest and on movement were reduced at $6 \mathrm{~h}$ postoperatively. In addition, TAP block reduced intravenous morphine consumption at $6 \mathrm{~h}$ and $12 \mathrm{~h}$ postoperatively [7]. Therefore, using a longer-acting local anesthetic, such as liposomal bupivacaine [2, 26, 27] or continuous TAP blocks [2, 10, 28] with catheters may provide extended duration, longer pain control in the postoperative period and, therefore, further decrease the need for postoperative opioids. Randomizedtrials are needed to further investigate the effect of continuous TAP blocks or liposomal bupivacaine on the pain control and the patients' recovery after hepatectomy.

Tominimizeconfounding factors and increase comparability, we elected to keep the external conditions and procedures identical between the two groups. In this investigation, sensory block was assessed $10 \mathrm{~min}, 20 \mathrm{~min}$ and $30 \mathrm{~min}$ after the block was placed, and one patent in group $\mathrm{T}$ was excluded from the final analysis because of a failed blockade. Mitchel et al. [19] conducted an experiment in awake volunteers and found that an ultrasound-guided OSTAP blockade can have a dermotomal span up to T4-L4 segments with maximal sensory loss after $30 \mathrm{~min}$. Lee et al. [16] found that the subcostal approach blocked a median of four segments (interquartile range 3-5), with the most cephalad being T8 (interquartile range T7-T9). Maximum dermatomal spread was observed at $30 \mathrm{~min}$. In this study, the OSTAP block in group $\mathrm{T}$ resulted in a distribution of sensory block ranging from $\mathrm{T} 5$ to $\mathrm{T} 11$, which is less than that reported by Wassef et al. [29]. The time for incision in this investigation was $40 \mathrm{~min}$ after OSTAP, which was at the peak of the blockade effect. No significant differences were observed in incision length, time from TAP to incision, operative time, estimated total intraoperative blood loss or amount of intravenous fluid administered between group $\mathrm{C}$ and group $\mathrm{T}$. The two anesthesiologists performing the OSTAP blocks or intraoperative anesthesia management were blinded to the study; and the nurses who recorded the parameters and the postoperative follow-up were also blinded to this investigation.

One of the main concerns about the OSTAP blockade is the systemic toxicity of the local anesthetics. The study by Griffiths et al. [30]reported potentially toxic ropivacaine concentrations following the use of TAP blocks in gynecologic surgery when a similar total dose of ropivacaine $(3 \mathrm{mg} / \mathrm{kg})$ was used. Toju et al. [31] found that the administration of ropivacaine at $3 \mathrm{mg} / \mathrm{kg}$ during OSTAP led to rapid increases in plasma concentration during the first $2 \mathrm{~h}$ after the blockade and the Cmax nearly reached the threshold for systemic toxicity. Ropivacaine is predominantly eliminated by extensive metabolism in the liver, which depends on hepatic blood flow as well as the degree of protein binding. Edouard et al. [32] reported that the resection of three or more liver segments was associated with a 53\% decrease in the free ropivacaine clearance. Therefore, the first limitation was that we did not measure plasma ropivacaine concentrations in group $\mathrm{T}$ perioperatively, although none of the 
patients had symptoms of local anesthetic systemic toxicity (e.g. tinnitus, seizures, cardiovascular collapse) either immediately following the OSTAP blocks or in the PACU postoperatively. In addition, patients in this investigation were not followed up beyond hospital discharge at postoperative day for potential chronic pain. Finally, these data represent the experience at a single academic institution with ASA III or less patients with relatively low BMI, and may not be generalizable to the broader international population.

\section{Conclusion}

The ultrasound-guided OSTAP block has become an important analgesic modality for upper abdominal surgery, such as the hepatectomy with a Mercedes incision. It provids an opioid-sparing analgesic effect without obvious side effects. However, the modest duration of a single shot OSTAP is a significant limitation. OSTAP with continuous catheterization or with local anesthetics of longer duration needs to be further investigated.

\section{Abbreviations}

ASA: American Society of Anesthesiologists classification; DBP: Diastolic blood pressure; HR: Heart rate; MAP: Mean arterial pressures; OSTAP: Oblique subcostal transversus abdominis plane; PACU: Post-anesthetic care unit; PCA: Patient-controlled analgesia; PONV: Postoperative nausea and vomiting; SBP: Systolic blood pressure

\section{Acknowledgements}

We would like to thank Sujuan Ye, Ling Cheng, Lina Zhu, Qinghe Zhou and Jinlei Li for their assistance in the collection with the study.

\section{Funding}

This study was supported by grants from National Natural Science Foundation of China (Grant No. 81400672) and The Health and Family Planning Commission of Zhejiang Province, China (Grant No. 2016ZDA006).

\section{Availability of data and materials}

The datasets used and/or analyzedduring the current study are available from the corresponding author on reasonable request.

\section{Authors' contributions}

JGG helped to conduct the study and write the manuscript. HIL helped to conduct the study. QQP conducted the study and helped to analyze the data. ZYF helped to design the study and was a major contributor in writing the manuscript. All authors read and approved the final manuscript.

\section{Ethics approval and consent to participate}

This study was approved by the Ethical Committee of Zhejiang University (Hangzhou, People's Republic of China) (Ref: 2013-662). Each patient read and signed a consent form before enrolment in the study.

\section{Consent for publication}

All authors consent to publish the manuscript.

\section{Competing interests}

The authors have indicated that they have no conflicts of interest regarding the content of this article.

\section{Publisher's Note}

Springer Nature remains neutral with regard to jurisdictional claims in published maps and institutional affiliations.

\section{Author details}

'Department of Anesthesiology and Pain Medicine, the First Affiliated Hospital, Zhejiang University School of Medicine, 79 Qing Chun Road, Hangzhou 310003, People's Republic of China. ${ }^{2}$ Department of Anesthesiology and Pain Medicine, the First People's Hospital of Beilun District, Ningbo, China.

Received: 24 March 2017 Accepted: 26 March 2018

Published online: 10 April 2018

\section{References}

1. Hughes M, McNally S, McKeown DW, Wigmore S. Effect of analgesic modality on outcome following open liver surgery: a systematic review of postoperative analgesia. Minerva Anestesiol. 2015;81:541-56.

2. Chou R, Gordon DB, de Leon-Casasola OA, Rosenberg JM, Bickler S, Brennan T, Carter T, Cassidy CL, Chittenden EH, Degenhardt E, Griffith S, Manworren R, McCarberg B, Montgomery R, Murphy J, Perkal MF, Suresh S, Sluka K, Strassels S, Thirlby R, Viscusi E, Walco GA, Warner L, Weisman SJ, Wu CL. Management of Postoperative Pain: a clinical practice guideline from the American pain society, the American Society of Regional Anesthesia and Pain Medicine, and the American Society of Anesthesiologists' committee on regional anesthesia, executive committee, and administrative council. J Pain. 2016;17:131-57.

3. Serag Eldin M, Mahmoud F, El Hassan R, Abdel Raouf M, Afifi MH, Yassen K, Morad W. Intravenous patient-controlled fentanyl with and without transversus abdominis plane block in cirrhotic patients post liver resection. Local Reg Anesth. 2014;7:27-37.

4. Niraj G, Kelkar A, Jeyapalan I, Graff-Baker P, Williams O, Darbar A, Maheshwaran A, Powell R. Comparison of analgesic efficacy of subcostal transversus abdominis plane blocks with epidural analgesia following upper abdominal surgery. Anaesthesia. 2011;66:465-71.

5. Rosero EB, Cheng GS, Khatri KP, Joshi GP. Evaluation of epidural analgesia for open major liver resection surgery from a US inpatient sample. Proc (Bayl Univ Med Cent). 2014;27:305-12.

6. Milan ZB, Duncan B, Rewari V, Kocarev M, Collin R. Subcostal transversus abdominis plane block for postoperative analgesia in liver transplant recipients. Transplant Proc. 2011:43:2687-90.

7. Baeriswyl M, Kirkham KR, Kern C, Albrecht E. The analgesic efficacy of ultrasound-guided Transversus Abdominis plane block in adult patients: a meta-analysis. Anesth Analg. 2015;121:1640-54.

8. De Oliveira GS Jr, Castro-Alves L, Nader A, Kendall MC, McCarthy RJ. Transversus abdominis plane block to ameliorate postoperative pain outcomes after laparoscopic surgery: a meta-analysis of randomized controlled trials. Anesth Analg 2014;118:454-463.

9. Abdallah FW, Chan WW, Brull R. Transversus abdominis plane block: a systematic review. Reg Anesth Pain Med. 2012;37:193-209.

10. Maeda A, Shibata SC, Wada H, Marubashi S, Kamibayashi T, Eguchi H, Fujino Y. The efficacy of continuous subcostal transversus abdominis plane block for analgesia after living liver donation: a retrospective study. J Anesth. 2016;30:39-46.

11. Liu LL, Gropper MA. Postoperative analgesia and sedation in the adult intensive care unit: a guide to drug selection. Drugs. 2003;63:755-67.

12. Urigel S, Molter J. Transversus abdominis plane (TAP) blocks. AANA J. 2014; 82:73-9.

13. Petersen PL, Mathiesen O, Torup H, Dahl JB. The transversus abdominis plane block: a valuable option for postoperative analgesia? A topical review. Acta Anaesthesiol Scand. 2010;54:529-35.

14. Torup H, Bøgeskov M, Hansen EG, Palle C, Rosenberg J, Mitchell AU, Petersen PL, Mathiesen O, Dahl JB, Møller AM. Transversus abdominis plane (TAP) block after robot-assisted laparoscopic hysterectomy: a randomised clinical trial. Acta Anaesthesiol Scand. 2015;59:928-35.

15. Hebbard P. Subcostal transversus abdominis plane block under ultrasound guidance. Anesth Analg. 2008;106:674-5.

16. Lee TH, Barrington MJ, Tran TM, Wong D, Hebbard PD. Comparison of extent of sensory block following posterior and subcostal approaches to ultrasound-guided transversus abdominis plane block. Anaesth Intensive Care. 2010;38:452-60.

17. Shin HJ, Oh AY, Baik JS, Kim JH, Han SH, Hwang JW. Ultrasound-guided oblique subcostal transversus abdominis plane block for analgesia after laparoscopic cholecystectomy: a randomized, controlled, observer-blinded study. Minerva Anestesiol. 2014;80:185-93. 
18. Chen CK, Tan PC, Phui VE, Teo SC. A comparison of analgesic efficacy between oblique subcostal transversus abdominis plane block and intravenous morphine for laparascopic cholecystectomy. A prospective randomized controlled trial. Korean J Anesthesiol. 2013:64(6):511.

19. Mitchell AU, Torup H, Hansen EG, Petersen PL, Mathiesen O, Dahl JB, Rosenberg J, Møller AM. Effective dermatomal blockade after subcostal transversus abdominis plane block. Dan Med J. 2012;59:A4404.

20. Jensen $\mathrm{K}$, Baek N, Jensen JT, Brglum J. Bilateral dual transversus abdominis plane block providing surgical anaesthesia for abdominal wall surgery. Anaesthesia. 2013;68:106-8.

21. Demirbas T, Bulutcu F, Dayangac M, Yaprak O, Guler N, Oklu L, Akyildiz M, Altaca G, Tokat Y, Yuzer Y. Which incision is better for livingdonor right hepatectomy? Midline, J-shaped, or Mercedes. Transplant Proc. 2013:45:218-21.

22. Li M, Wan L, Mei W, Tian Y. Update on the clinical utility and practical use of ropivacaine in Chinese patients. Drug Des Devel Ther. 2014;8:1269-76.

23. McDonnell JG, O'Donnell B, Curley G, Heffernan A, Power C, Laffey JG. The analgesic efficacy of transversus abdominis plane block after abdominal surgery: a prospective randomized controlled trial. Anesth Analg. 2007;104: 193-7.

24. Støving K, Rothe C, Rosenstock CV, Aasvang EK, Lundstrøm LH, Lange KH. Cutaneous sensory block area, muscle-relaxing effect, and block duration of the Transversus Abdominis plane block: a randomized, blinded, and placebo-controlled study in healthy volunteers. Reg Anesth Pain Med. 2015; 40:355-62.

25. McDonnell JG, Curley G, Carney J, Benton A, Costello J, Maharaj CH, Laffey $J G$. The analgesic efficacy of transversus abdominis plane block after cesarean delivery: a randomized controlled trial. Anesth Analg. 2008;106: 186-91.

26. Hutchins J, Delaney D, Vogel Rl, Ghebre RG, Downs LS Jr, Carson L, Mullany $\mathrm{S}$, Teoh D, Geller MA. Ultrasound guided subcostal transversus abdominis plane (TAP) infiltration with liposomal bupivacaine for patients undergoing robotic assisted hysterectomy: a prospective randomized controlled study. Gynecol Oncol. 2015;138:609-13.

27. Hutchins J, Vogel Rl, Ghebre R, McNally A, Downs LS Jr, Gryzmala E, Geller MA. Ultrasound-guided subcostal transversus abdominis plane infiltration with liposomal bupivacaine for patients undergoing robotic-assisted hysterectomy: a retrospective study. Int J Gynecol Cancer 2015;25:937-941.

28. Farag E, Guirguis MN, Helou M, Dalton JE, Ngo F, Ghobrial M, O'Hara J, Seif J, Krishnamurthi V, Goldfarb D. Continuous transversus abdominis plane block catheter analgesia for postoperative pain control in renal transplant. J Anesth. 2015;29:4-8.

29. Wassef M, Lee DY, Levine JL, Ross RE, Guend H, Vandepitte C, Hadzic A, Teixeira J. Feasibility and analgesic efficacy of the transversus abdominis plane block after single-port laparoscopy in patients having bariatric surgery. J Pain Res. 2013;6:837-41.

30. Griffiths JD, Barron FA, Grant S, Bjorksten AR, Hebbard P, Royse CF. Plasma ropivacaine concentrations after ultrasound-guided transversus abdominis plane block. Br J Anaesth. 2010;105(6):853.

31. Toju K, Shiraishi K, Hakozaki T, Isosu T, Murakawa M. Plasma ropivacaine concentration following ultrasound-guided subcostal transversus abdominis plane block in adults. J Anesth. 2015;29:146-8.

32. Ollier E, Heritier F, Bonnet C, Hodin S, Beauchesne B, Molliex S, Delavenne X. Population pharmacokinetic model of free and total ropivacaine after transversus abdominis plane nerve block in patients undergoing liver resection. Br J Clin Pharmacol. 2015;80:67-74.

\section{Submit your next manuscript to BioMed Central and we will help you at every step:}

- We accept pre-submission inquiries

- Our selector tool helps you to find the most relevant journal

- We provide round the clock customer support

- Convenient online submission

- Thorough peer review

- Inclusion in PubMed and all major indexing services

- Maximum visibility for your research

Submit your manuscript at www.biomedcentral.com/submit 